\title{
DETECÇÃO E CARACTERIZAÇÃO MOLECULAR DO HERPESVÍRUS HUMANO TIPO 6 (HHV-6) EM TECIDO GENGIVAL DE PACIENTES ACOMETIDOS POR DOENÇA PERIODONTAL
}

Dissertação apresentada ao Programa de Pós-Graduação em Microbiologia do Instituto de Ciências Biomédicas da Universidade de São Paulo, para obtenção do título de Mestre em Ciências.

Área de Concentração: Microbiologia

Orientador: Dr. Klaus Eberhard Stewien 


\section{Resumo}

SILVA, L. A. Detecção e caracterização do herpes vírus humano tipo 6 (HHV-6) em tecido gengival de pacientes acometidos por doença periodontal. 2008. $81 \mathrm{f}$. Dissertação (Mestrado em Microbiologia) - Instituto de Ciências Biomédicas, Universidade de São Paulo, São Paulo, 2008.

Análise: Estudos recentes têm sugerido que os herpesvírus podem estar envolvidos na ocorrência e progressão de diferentes formas de doença periodontal. Objetivos: $O$ objetivo do presente estudo foi investigar a presença de herpesvírus HHV-6 em biópsias gengivais de pacientes afetados por periodontite crônica e verificar a variabilidade genética das amostras positivas para HHV-6 (HHV-6 A e HHV-6 B). Como controle, biópsias gengivais de sujeitos periodontalmente saudáveis foram analisadas. Materiais e Métodos: Biópsias gengivais foram colhidas de 60 voluntários: 30 casos afetados por periodontite crônica e 30 casos periodontalmente saudáveis. Cada caso contribuiu com 1 biópsia envolvendo o epitélio e tecido conjuntivo da bolsa periodontal contendo profundidade $\geq$ a $5 \mathrm{~mm}$ e apresentando sangramento à sondagem após o exame clínico; a outra biópsia controle foi concedida de local com profundidade clínica de sondagem $\leq$ a $3 \mathrm{~mm}$ não apresentando sangramento. Para extração e purificação do DNA viral foi utilizado o kit da Invitrogen ${ }^{\circledR}$ (Charges Switch ${ }^{\circledR} g$ DNA Mini Tissue kit). O DNA extraído foi amplificado utilizando as técnicas de PCR e nested-PCR. Os produtos amplificados foram seqüenciados utilizando o kit Big Dye Terminator (Applied Biosystems). As seqüencias obtidas foram alinhadas com o auxílio do Programa Sequence Navigator e comparadas com amostras padrão do Gene Bank. Resultados: Após a análise de 60 amostras, seqüências de DNA de HHV-6 foram detectadas em locais periodontalmente saudáveis 4/30 (13,3\%), e em locais com doença periodontal 2/30 (6,7 \%); seis produtos positivos da nested-PCR foram seqüenciados e apresentaram homologia para a variante B. Conclusões: $O$ presente estudo demonstrou que o tecido gengival pode agir como reservatório para HHV-6. Nossos dados sugerem que estudos adicionais sejam realizados a fim de consolidar uma associação entre os subtipos de herpesvírus investigados com a doença periodontal destrutiva.

Palavras-Chaves: HHV-6, Doença periodontal, Herpesvírus, Reação da polimerase em cadeia. 


\begin{abstract}
SILVA, L. A. Detection and molecular caracterisation of human HHV-6 herpesvirus in gengival tissues of pacients affected by periodontal disease. 2008. 81 f. Master thesis (Microbiology) - Instituto de Ciências Biomédicas, Universidade de São Paulo, São Paulo, 2008.
\end{abstract}

Analysis: Recent studies have suggested that the herpesvirus may be involved in the occurrence and progression of different forms of periodontal disease. Objectives: The purpose of this study was to investigate the HHV-6 herpesvirus presence in gingival biopsies of patients affected by chronic periodontitis and to ascertain the positive sample's genetic variability for HHV-6 (HHV-6A and HHV-6B). As a control, biopsies of gingival periodontally healthy subjects were examined. Materials and Methods: gingival biopsies were taken from 60 volunteers: 30 cases affected by chronic periodontitis and 30 cases periodontally healthy. Each case contributed with 1 biopsy involving the epithelium and connective tissue of periodontal pocket depth containing $\geq 5 \mathrm{~mm}$ and stating the bleeding on probing after the clinical examination; the other control biopsy was granted from local with clinical survey depth of $\leq 3 \mathrm{~mm}$ showed no bleeding. For extraction and purification of viral DNA was used the Invitrogen ${ }^{\circledR}$ kit (Charges Switch ${ }^{\circledR}$ g Mini Tissue DNA kit). The extracted DNA was amplified using the techniques of PCR and nested-PCR. The amplified products were sequenced using the Big Dye Terminator kit (Applied Biosystems). The sequences obtained were aligned with the aid of the Sequence Navigator Program and compared with standard samples of Gene Bank. Results: After the analysis of 60 samples, DNA sequences of HHV-6 were found in places periodontally healthy 4/30 (13,3\%), and in places with periodontal disease $2 / 30(6,7 \%)$; six positive products of nested-PCR were sequenced and showed homology for variant B. Conclusions: This study has demonstrated that the gingival tissue may act as a reservoir for HHV-6. Our data suggest that additional studies must be conducted to consolidate an association between subtypes of herpesvirus investigated and the destructive periodontal disease.

Keywords: HHV-6, Periodontal disease, Herpesvirus, Polymerase chain reaction 


\section{Introdução}

A Periodontite é uma doença infecciosa na qual bactérias específicas (SOCRANSKY e HAFFAJEE, 1992) e mecanismos imunológicos relacionados ao hospedeiro estão associados. Alguns estudos relacionaram o envolvimento de certos vírus na etiologia e patogênese da doença periodontal, sendo que os pioneiros nessa linha de pesquisa foram Parra e Slots em 1996.

Todavia, sabe-se que as diferentes manifestações clínicas da periodontites podem possuir diferentes fatores de risco e uma série de co-fatores envolvidos. Dessa maneira é importante estudar indicadores de risco para a doença periodontal, para que o tratamento e a profilaxia da doença obtenham sucesso (SLOTS e CONTRERAS, 2000).

O herpesvírus humano tipo $6(\mathrm{HHV}-6)$ foi descoberto em 1986, por SALAHUDDIN e colaboradores, O HHV-6 possui duas variantes: A e B, as mesmas infectam preferencialmente linfócitos CD4+, a replicação viral nas glândulas salivares é observada por HHV-6B (EFSTATIOU et al., 1988; LAWRENCE et al., 1990; PELLET e BLACK, 1996).

Em 1988, o HHV-6 foi identificado como agente etiológico do Exantema Súbito (YOSHIDA et al., 1989).

Poucos estudos estão disponíveis sobre a ocorrência de HHV-6 nos tecidos periodontais, alguns deles sugerem que o HHV-6 apresenta pouca ou nenhuma associação com a maioria dos tipos de doença periodontal destrutiva (CONTRERAS et al., 1996; CONTRERAS et al., 1997; CONTRERAS et al., 1999).

O presente estudo foi realizado com a intenção de acrescentar dados sobre a ocorrência de HHV-6 em doenças periodontais, pois os mesmos ainda são escassos na literatura. 


\section{Revisão de Literatura}

\subsection{Doença Periodontal}

A doença periodontal (DP) é uma doença de grande prevalência na população brasileira (Susin et al., 2004), dessa maneira se faz importante o estudo das periodontopatias em saúde coletiva no Brasil. Em muitos países índices que avaliam o impacto das condições bucais na vida dos indivíduos justificam que a prevenção, o diagnóstico e tratamento correto das doenças bucais devem ser medidas consideradas e aplicadas em saúde bucal (ARAÚJO et al., 2006).

O termo DOENÇA PERIODONTAL é utilizado para designar todas as doenças que afetam o periodonto (do grego perio $=$ ao redor; e odonto $=$ dente). As infecções periodontais representam um desafio, tanto para o doente como para o cirurgiãodentista. Diferentemente da superfície externa da maior parte do corpo, as camadas externas do dente não esfoliam e, assim, facilitam a colonização bacteriana. Deste modo, representam uma ameaça potencial aos tecidos periodontais e ao próprio hospedeiro (LINDHE et al., 2005).

\subsection{O Periodonto}

O periodonto é definido como o conjunto de tecidos que protegem e sustentam os dentes. Dessa maneira temos o periodonto de proteção que compreende a junção dento-gengival (porção gengival em contato com o dente) e o periodonto de sustentação que compreende o ligamento periodontal, o cemento e o osso alveolar. O cemento está disposto na superfície dentária e é considerado parte do periodonto porque, juntamente com o osso, sustenta as fibras do ligamento periodontal (LINDHE et al., 2005).

Cada elemento periodontal possui componentes especializados, com funções específicas, dinamicamente relacionados (Figura 1 e 2). 


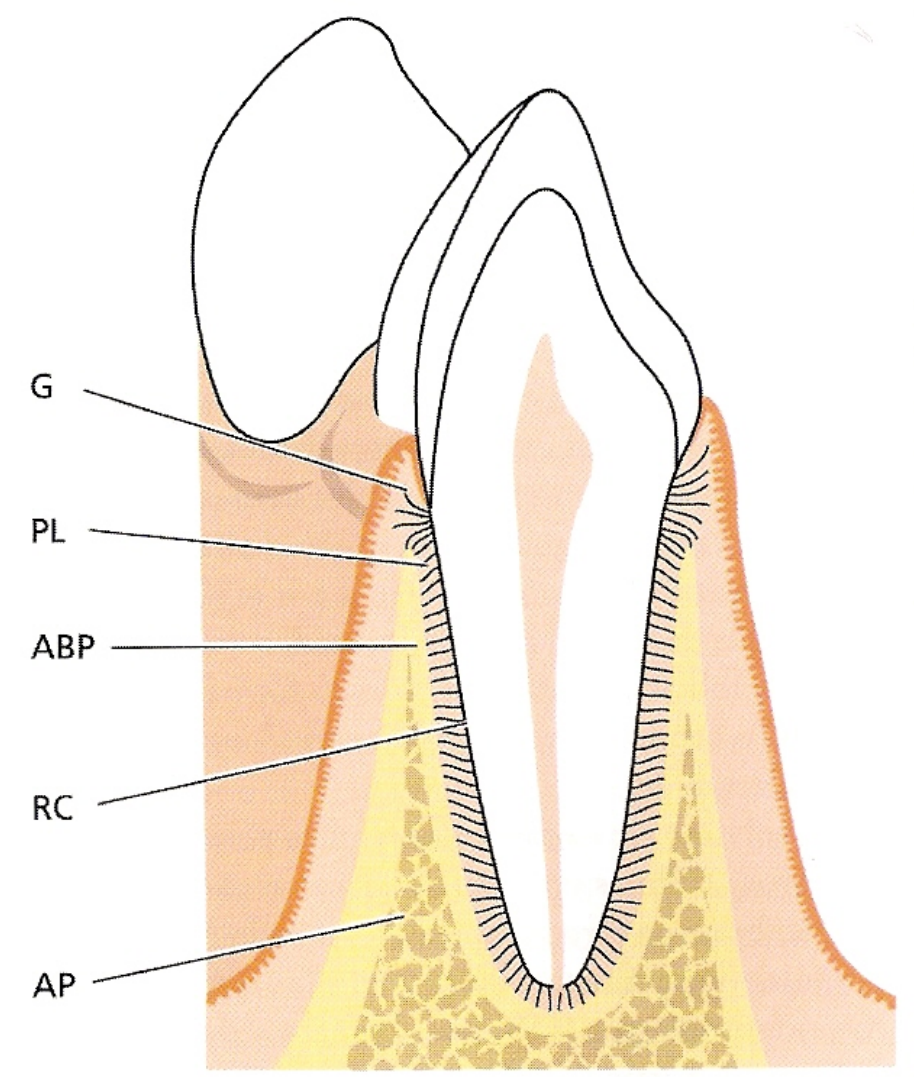

Figura 1- Esquema ilustrando os elementos do periodonto: a gengiva $(\mathrm{G})$, o ligamento periodontal (PL), o cemento radicular (RC), o osso alveolar que é composto por processo alveolar (AP) e osso alveolar propriamente dito (ABP) (LINDHE et al., 2005). 


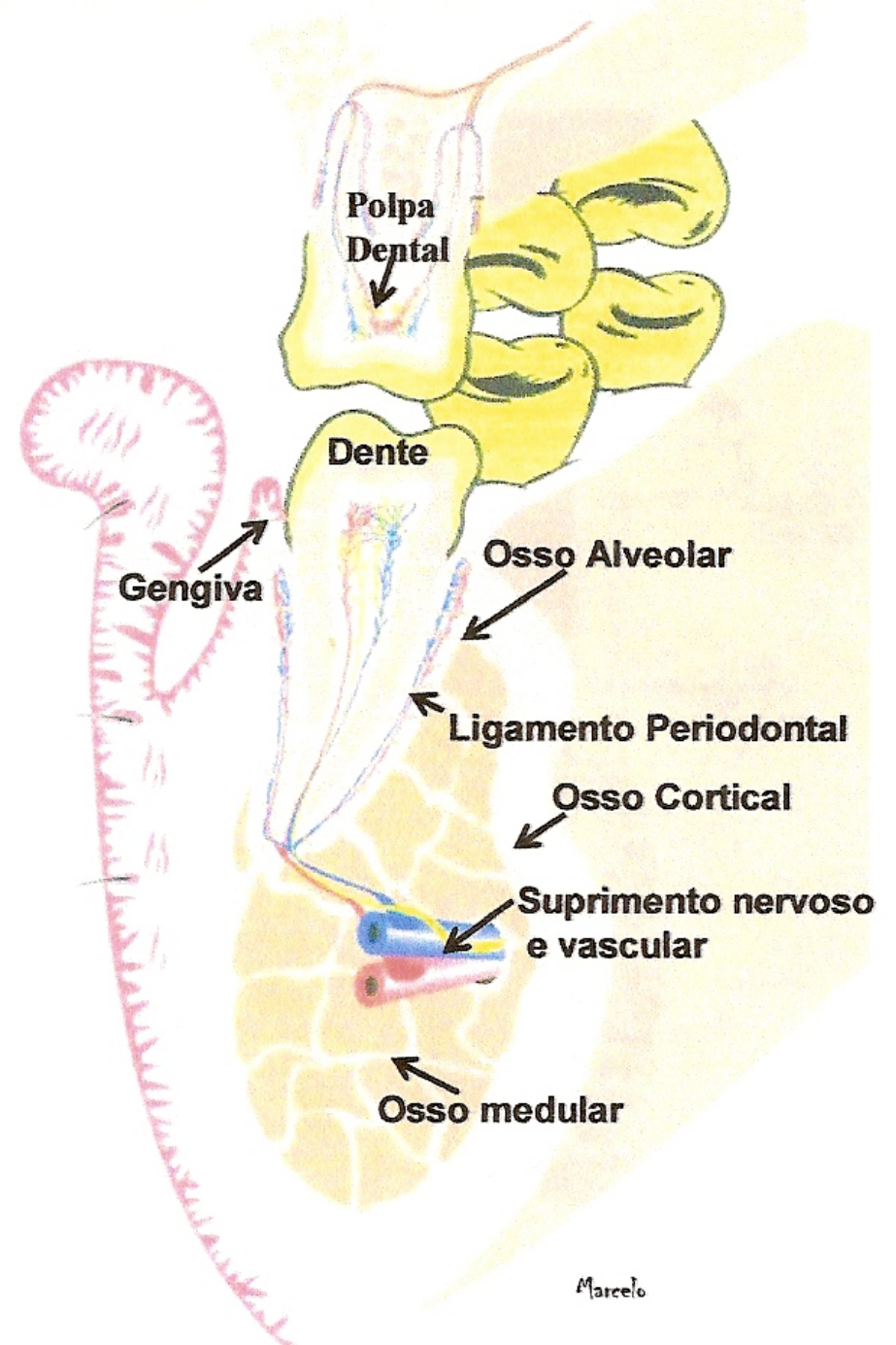

Figura 2- Esquema ilustrando os elementos do periodonto: fibras do ligamento periodontal inseridas no cemento radicular e no osso alveolar (periodonto de sustentação) e a gengiva representando o periodonto de proteção ( SIQUEIRA, 2001). 
A junção dento-gengival é a adaptação da mucosa oral que compreende os tecidos epitelial e conjuntivo. O epitélio é dividido em três compartimentos funcionais: gengival, sulcular e epitélio juncional. $\mathrm{O}$ epitélio juncional tem a importante função de isolar os tecidos periodontais do restante da cavidade oral. Assim, sua integridade é essencial para manter a saúde do periodonto. O tecido conjuntivo subjacente ao epitélio juncional é estruturalmente diferente daquele que suporta o epitélio oral gengival: mesmo em condições clinicamente normais, apresenta um infiltrado inflamatório. Estas células inflamatórias, como os leucócitos polimorfonucleares e linfócitos $T$, continuamente extravasam das vênulas pós-capilares e migram em direção ao epitélio juncional para dentro do sulco gengival (FABRI, 2007; BARTOLD et al., 2000; MC CULLOCH et al., 2000).

O cemento é o tecido conjuntivo duro, avascular que recobre a raiz dos dentes e serve, primariamente, para insersão das fibras do ligamento periodontal. Possui $50 \%$ de mineral (apatita) e 50\% de matriz orgânica (predominantemente colágeno tipo I) (FABRI, 2007; NANCIE e BROSSHARDT, 2006).

O ligamento periodontal é formado por tecido conjuntivo frouxo, especializado, situado entre o cemento e o osso: é o único entre os vários sistemas de ligamentos e tendões do corpo que se interpõe entre dois tecidos duros. Possui pequena dimensão (0,15 a 0,38 mm de espessura) e importantes funções: suporta o dente no alvéolo, resiste à força mastigatória, atua como proprioceptor necessário para o posicionamento mandibular durante a mastigação e constitui um reservatório de células importantes para homeostase e regeneração (osteoclastos, osteoblastos, fibroblastos, restos epiteliais de Malassez, monócitos, células mesenquimais indiferenciadas, cementoblastos e odontoblastos) (FABRI, 2007; MCCULLOCH, 2000; NANCIE e BROSSHARDT, 2006).

O processo alveolar é a porção óssea dos maxilares que contém os alvéolos para os dentes. Constituído por uma porção cortical de osso compacto, outra porção esponjosa central e uma porção que reveste os alvéolos (osso alveolar). A porção cortical encontra-se com a porção alveolar na crista alveolar (FABRI, 2007; NANCIE e BROSSHARDT, 2006). O aspecto histológico dos tecidos periodontais e gengiva clinicamente saudável está representado em detalhes na figura 3. 


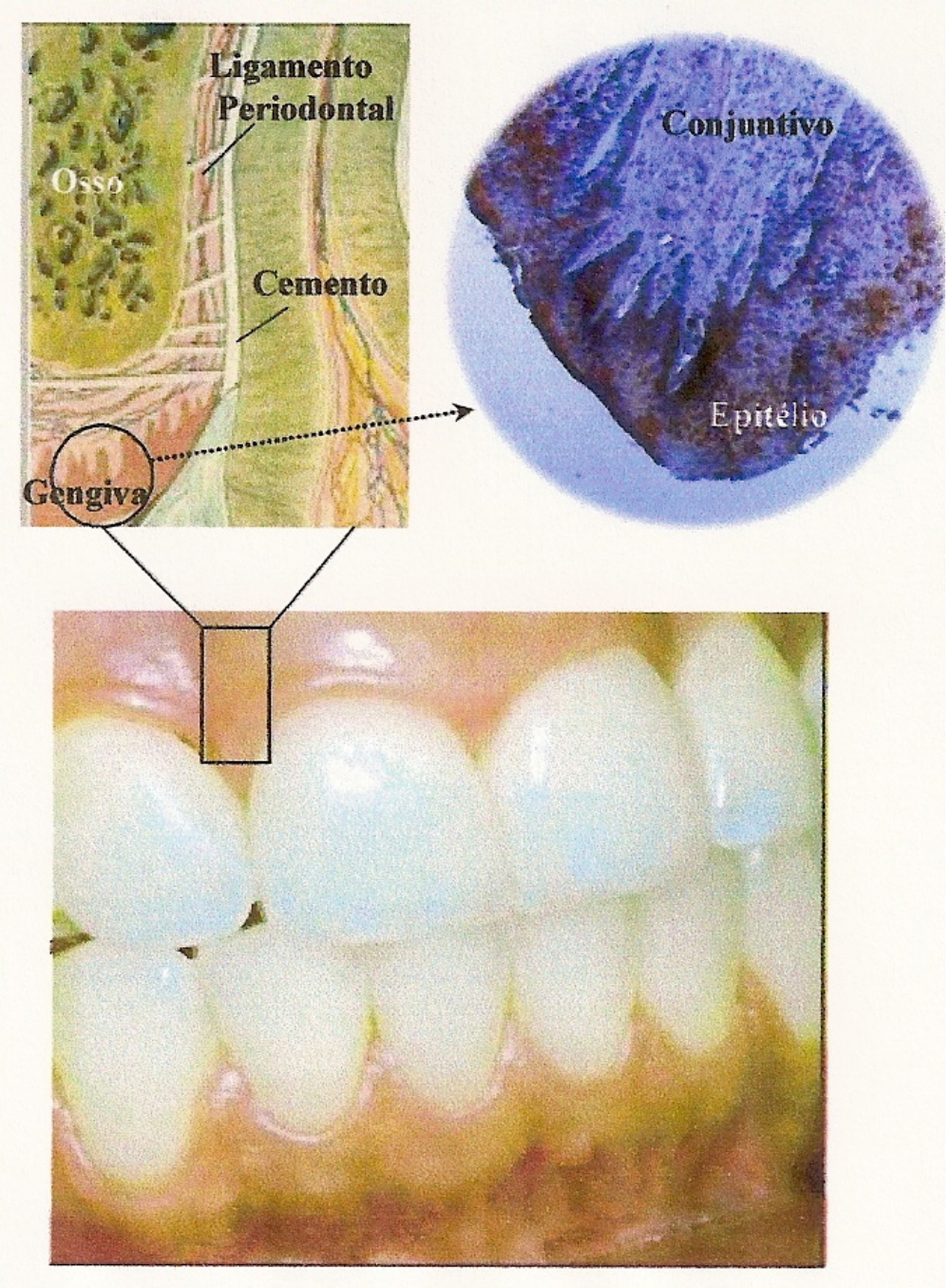

Figura 3- Representação esquemática do aspecto histológico dos tecidos periodontais e gengiva clinicamente saudável (FABRI, 2007). 


\subsection{Classificação das doenças periodontais}

As doenças periodontais são também conhecidas como gengivites e periodontites, podem ser agudas ou crônicas, sua etiologia é multifatorial e compõem extensa classificação, com critérios diagnósticos que permitem a individualização de cada uma delas (ARMITAGE, 1999). A classificação geral das condições e doenças periodontais está detalhada no Quadro 1. 
Quadro 1 - Classificação das Condições e Doenças Periodontais.

I- Doenças Gengivais:

A-Doenças gengivais induzidas por placa bacteriana

1-Gengivite associada somente com placa bacteriana

a- sem outros fatores locais

b- com fatores locais

2-Doenças Gengivais modificadas por fatores sistêmicos

a- Associada com o sistema endócrino

$$
\begin{aligned}
& \text { a.1- Puberdade } \\
& \text { a.2- Menstruaçăo } \\
& \text { a.3- Gravidezi gengivite/ granuloma piogênico } \\
& \text { a.4- Diabetes Mellitus }
\end{aligned}
$$

3- Doenças gengivais modificadas por medicaçũes

$$
\text { a-Drogas }
$$

$$
\text { a.1- Hiperplasia }
$$

a.2-Gengivite

a.2.1- anticoncepcionais

a.2.2-outros

4- Doenças gengivais modificadas por má nutriçăo

a- Avitaminose C

b- Outros

B- Doenças gengivais não induzidas por piaca bacteriana

1- Doenças gengivais de origem bacteriana especifica

a-Neisseria gonorrhea

b- Treponema pallidum

c- outros

2- Doenças gengivais de origen virótica

a- Herpética a.1- Gengivoestomatite herpética primária

a.2- Herpes bucal recorrente

a.3- varicela/ Herpes zoster

3- Doenças gengivais de origem fúngica

a- Cânđida

a. 1- Candidose gengival generalizada

b- Eritema gengival linear

c- Histoplastnose

d-Outros

4- Lesão gengival de origem genética

a- Fibromatose gengival hereditária

b- Outros

5- Manifestação gengival de condições sistêmicas

a- Alterações mucocutâneas: liquen plano; penfigóide, pênfigo vulgar, eritema multiforme, lupus eritematoso, pênfigo vulgar, eritema muth
induçăo de drogas, outros

b- Reações alérgicas

b.1- materiais restauradores: mercúrio, niquel, acrílico, outros

b.2-relacionados a dentifricios, bochechos, goma de mascar, alimentos, conservantes

b.3- outros

6- Lesões traumáticas( factícia, iatrog6enica, acidental)

a- química

b- física

c- térmica

7. Reação de corpo estranho

8. Nerhuma outra especificada
II. Periodontite Crônica

A- Localizada

B- Generalizada

III- Periodontite Agressiva

A- Localizada

IV-Periodontite como manifestaçấo de doenças sistêmicas

A- Associada à doenças hematológicas

1- Neutropenia adquirida

2- Leucemi

B- Associada com alteraçōes genéticas

1 - Neutropenia familiar e cíclica, sindrome de Down; Sindrome de deficiência da adesão de leucócitos; sindrome de Papillon-Lefévre; Síndrome de Chediak Higashi, Histiocitose; Doença de armazename glicogênio; Agranulocitose; genetica infantil; (tipo IV e VIII); Hipofostasia; outros

C- Nenhuma outra especificada

V- Doenças periodontais Necrosantes

A- Gengivite Ulcerativa Necrozante (GUN)
B- Periodontite Ulcerativa Necrozante (PUN)

VI- Abscessos Periodontais

A- Gengival

B- Periodontal

C- Pericoronário

VII- Periodontite associada com lesão endodôntica

A- Lesão combinada Perio-endodôntica
V1Y1- Doformadades c condlyos adquiridas

A- Fafores localizadios, relacionados ao dente, que modificam on predispóm a doença gengival e periodontal induzida por placa bacteriana

1 - fatores anatômicos dentários

3- fratura radicular

4- reabsorção cervical da raiz e do cemento

B- Deformidades mucogengivais e condiç̧es ao redor do dente

1- Retração gengival

a- Superfice vestibular ou lingual
b- Inierproximal

2- Gengiva inserida insuficiente

3. Vestibulo raso

- Freio/ brida anormal

a- Pseudobolsa; Margem gengiva inconsistente; Hiperplasia gengival

6. Cor anormal

C- Deformidades e condiçồes mucogengivais em áreas edêntulas

1- Deformidade vertical/horizontal

- Insuficiência de gengiva/tecido queratinizado

- Aumento gengival/Tecido mole

4. Freio/ brida anormal

6- Vestibulo ras

D- Traumatismo Oclusal

1- Traumatismo oclusal primário

2- Traumatismo oclusal secundário

Fonte: ARMITAGE, 1999; FABRI 2007. 


\subsection{Epidemiologia das doenças periodontais}

A pesquisa epidemiológica em periodontia deve atender à incumbência de fornecer dados sobre a prevalência das doenças periodontais em diferentes populações, ou seja, a freqüência com que ocorrem, bem como a gravidade de tais condições, isto é, o nível de ocorrência das alterações patológicas; esclarecer aspectos relativos à etiologia e aos fatores determinantes de desenvolvimento dessas doenças (fatores de risco e causais) e proporcionar a documentação referente à eficácia das medidas preventivas e terapêuticas direcionadas contra tais doenças em uma determinada população (LINDHE et al., 2005).

Dados epidemiológicos mostram alta prevalência da doença periodontal na população adulta em geral (LÖE et al., 1992, ALBANDAR e RAMS, 2002).

Em levantamento epidemiológico populacional sobre saúde oral da população urbana no sul do Brasil cuja amostragem foi de 612 indivíduos, faixas etárias entre 14 e 19 anos, 20 e 29 anos foram classificadas como grupos com fatores de risco para DP se possuíssem 4 ou mais dentes com perda de nível clínico de inserção(NCI) $\geq m m 4$ e $\geq 5 \mathrm{~mm}$ respectivamente. A DP ocorreu igualmente entre homens e mulheres, mas duas vezes mais prevalente em indivíduos não-brancos do que em brancos. Nos grupos de faixa etária entre 20 e 24 anos, 25 e 29 anos, os sujeitos com fatores de risco para periodontite agressiva tiveram uma prevalência significante de perda dental (90,2\% versus $40,4 \%$ e $86,1 \%$ versus $43,4 \% \mathrm{P}<0,01)$. Os indivíduos com fatores de risco para periodontite agressiva também tiveram porcentagens significativamente maiores em locais com $\mathrm{PB}(\mathrm{P}<0,0001)$, sangramneto gengival $(\mathrm{P}<0,05)$, e cálculo supragengival $(\mathrm{P}<0,0001)$ do que sujeitos saudáveis (SUSIN C e ALBANDAR JM, 2005).

Em outro estudo sobre saúde oral da população urbana brasileira, 853 indivíduos dentados, com faixa etária de 30 a 103 anos, avaliou-se a perda do NCI correlacionando dados clínicos com risco de exposição ambiental, comportamental e demográfica para DP. Esse estudo mostrou que na faixa etária de 40 a $49 \geq 50$ anos de idade tiveram 3,0 e 5,9 vezes maior risco para perda do NCI; e 7,4 e 25,4 vezes maior risco para perda do NCI severa, comparados com os indivíduos de 30 a 39 anos de idade. Fumantes de cigarro moderados tiveram um risco significantemente maior para perda do NCI moderada (média relativa de risco $=2,1$ ) e severa onde a média relativa de risco $=3,4$; e fumante pesados tiveram um maior risco para perda do nível NCI (média relativa de risco $=8,2$ ) comparado com não fumantes. Um risco significativamente maior para 
perda do NCI foi encontrado em homens, com nível sócio-econômico baixo, com histórico de visitas irregulares ao dentista. Nesse estudo o status diabetes e raça não mostraram associações significantes com o NCI (SUSIN C et al., 2004).

O Ministério da Saúde do Brasil realizou um estudo epidemiológico no país cujo período foi de 2002 a 2003, a porcentagem de indivíduos sem problemas periodontais, nas faixas etárias de 15 a 19, 35 a 44 e 65 a 74 anos de idade, foi respectivamente: $46,2 \%, 21,9 \%$ e 7,9\%. O mesmo estudo concluiu que o aumento da idade eleva o número de dentes perdidos sendo que na faixa etária de 65 a 74 anos mais de $80 \%$ dos sextantes examinados eram desdentados ou apresentavam apenas um dente funcional PROJETO SB BRASIL (Ministério da Saúde, 2003).

\subsection{Patogênese da Doença Periodontal}

A doença periodontal (DP) é uma doença infecciosa que envolve bactérias específicas (SOCRANSKY e HAFFAJEE, 1992) e características imunológicas inerentes ao hospedeiro. A progressão da doença ocorre pela interação de fatores como idade, sexo, genética, fatores socioeconômicos e determinadas doenças sistêmicas (LÖE et al., 1965; KINANE et al., 2006). Com base nessas pesquisas os principais microrganismos envolvidos com periodontopatias são bactérias, onde algumas leveduras podem estar presentes, sem terem obrigatoriamente uma participação efetiva. Contudo, pouca ou nenhuma importância tem sido destinada ao envolvimento de certos vírus na etiologia e patogênese da doença periodontal (PARRA e SLOTS, 1996).

A DP é caracterizada por um processo infeccioso e destrutivo dos tecidos periodontais, presença de processo inflamatório nos tecidos periodontais de proteção (gengiva e mucosa alveolar) e suporte (ligamento periodontal, osso-alveolar e cemento radicular). A periodontite crônica (PC) caracteriza-se pela progressão lenta do processo destrutivo da DP (ARMITAGE, 1999).

$\mathrm{Na}$ etiologia para as doenças periodontais, a presença das bolsas periodontais são atribuídas pela presença de microrganismos e seus produtos, que juntos causam alterações patológicas nos tecidos e aprofundam o sulco gengival (GARCIA et al., 1998).

Pacientes que apresentam redução no número ou na função dos leucócitos polimorfonucleares podem desenvover DP grave. Muitas drogas como fenitoína, 
nifedipina e ciclosporina, associadas à placa bacteriana $(\mathrm{PB})$, predispõem ao crescimento gengival. Alterações nos níveis hormonais podem aumentar a gravidade da inflamação gengival. O Diabettes Mellitus, pela hiperglicemia crônica, provoca alterações estruturais (modificação da função capilar, redução da perfusão sangüínea dos tecidos, estresse oxidativo, etc.) que aceleram a destruição periodontal (SOUTHERLAND et al., 2006; KINANE et al.; 2006)

O tabagismo também está relacionado no desenvolvimento da DP, indivíduos fumantes podem ter aumento na gravidade da DP (KINANE et al., 2006). Muitas substâncias presentes no cigarro (nicotina, monóxido de carbono e o cianeto de hidrogênio) diminuem os mecanismos de defesa do indivíduo, como disfunção nos mecanismos da resposta inflamatória e consequentemente redução do processo de cicatrização tecidual (RIVERA-HIDALGO, 1986; FABRI, 2007).

$\mathrm{O}$ aspecto emocional, como estresse psicológico, pode ter efeito direto ou indireto sobre os mecanismos de defesa do indivíduo, dessa maneira pode ocorrer uma agudização ou evolução da DP (KINANE et al., 2006).

A evolução das doenças periodontais está relacionada com imunodepressão do hospedeiro, esses aspectos da resposta inflamatória e imunológica têm fatores genéticos definidos (YOSHIE et al., 2007). O polimorfismo do gene interleucina-1 (IL-1) parece ser um marcador genético importante para DP. Vários estudos apontam uma relação entre a DP e a presença do polimorfismo do gene IL-1 (YAMAZAKI et al., 2004; TAKASHIBA et al., 2006).

Nas periodontites, a reação inflamatória dos tecidos é perceptível tanto clinicamente quanto microscopicamente, essa resposta inflamatória traduz uma reação do hospedeiro aos microrganismos presentes e a liberação de seus produtos metabólicos. Através de estudos estima-se que 400 espécies diferentes são capazes de colonizar a cavidade da boca, sendo que a contagem nos sítios subgengivais varia de cerca de 1.000, em sulco raso sadio, a mais de 100.000.000, em bolsas periodontais profundas. $\mathrm{O}$ relacionamento entre a microbiota periodontal normal e o hospedeiro, de um modo geral são favoráveis; em determinadas situações um tipo de microrganismo é introduzido no ambiente periodontal, prolifera-se, exibindo mecanismos que levam à destruição dos tecidos periodontais (LINDHE et al., 2005).

A deposição microbiana na superfície dental limpa ocorre de maneira dinâmica, após a higienização das superfícies dentárias, em poucas horas forma-se uma película composta por glicoproteínas e proteínas salivares e do fluido crevicular, que possibilita 
a adesão bacteriana (película adquirida). As bactérias aderem-se umas as outras através de interações específicas, muitas vezes o microambiente favorece a instalação de um determinado microrganismo em detrimento de outro, onde percebemos mecanismos de sucessão microbiana, dessa maneira temos a formação do biofilme dental. O biofilme é uma organização microbiana contendo áreas de altas e baixas biomassas bacterianas entrelaçadas, com canais aquosos de diferentes tamanhos, que nutrem a colônia bacteriana e facilitam o movimento dos produtos metabólicos. Sua estrutura torna-o resistente a surfactantes, antibióticos, mecanismos de opsonização e fagocitose (DARVEU et al., 1997; DONLAN e COSTERTON, 2002; MARSH, 2004).

Os microrganismos mais comumente encontrados no periodonto doente estão listados no quadro 2 e figura 4. 
Quadro 2 - Espécies subgengivais associados com saúde, gengivite e periodontite.

\begin{tabular}{|c|c|c|}
\hline Saúde & Gengivite & Periodontite \\
\hline Streptococcus oralis & Streptococcus oralis & Porphyromonas gingivalis \\
\hline Streptococcus sanguis & Streptococcus sanguis & $\begin{array}{l}\text { Actinobacillus } \\
\text { actinomycetemcomitans } \\
\text { sorotipo b }\end{array}$ \\
\hline Streptococcus mitis & Streptococcus mitis & Bacteróides forsythus \\
\hline Streptococcus gordonii & Streptococcus intermedius & PRO spirochete \\
\hline Streptococcus mutans & Capnocytophaga ochracea & Treponema denticola \\
\hline Streptococcus anginosus & Capnocytophaga gingivalis & Prevotella intermédia \\
\hline Streptococcus intermedius & Campylobacter gracilis & Prevotella nigrescens \\
\hline Gemella morbillorum & Prevotella loescheii & Campylobacter rectus \\
\hline Rothia dentocariosa & Peptostreptococcus micros & Peptostreptococcus micros \\
\hline Actinomyces naeslundii & Eubacterium nodatum & $\begin{array}{l}\text { Fusubacterium nucleatum } \\
\text { subespécie Vincentii }\end{array}$ \\
\hline Actinomices gerencseriae & Actinomyces naeslundii & $\begin{array}{l}\text { Fusubacterium nucleatum } \\
\text { subespécie Nucleatum }\end{array}$ \\
\hline Actinomyces odontolyticus & Actinomyces israelii & Selenomonas noxia \\
\hline Peptostreptococcus micros & Campylobacter concisus & Selenomonas flueggeii \\
\hline Eubacterium nodatum & Actinomyces odontolyticus & Espécies entéricas \\
\hline Capnocytophaga ochracea & $\begin{array}{l}\text { Fusobacterium nucleatum } \\
\text { subespécie Nucleatum }\end{array}$ & Fusobacterium alocis \\
\hline Capnocytophaga gingivalis & Eubacterium brachy & Lactobacillu uli \\
\hline Campylobacter gracilis & Eikenella corrodens & Veillonella párvula \\
\hline $\begin{array}{l}\text { Fusobacterium nucleatum } \\
\text { subsp. Polymorphum }\end{array}$ & $\begin{array}{l}\text { Actinobacillus } \\
\text { actinomycetemcomitans } \\
\text { sorotipo a }\end{array}$ & \\
\hline
\end{tabular}

Fonte: DARVEU et al., 1997. 


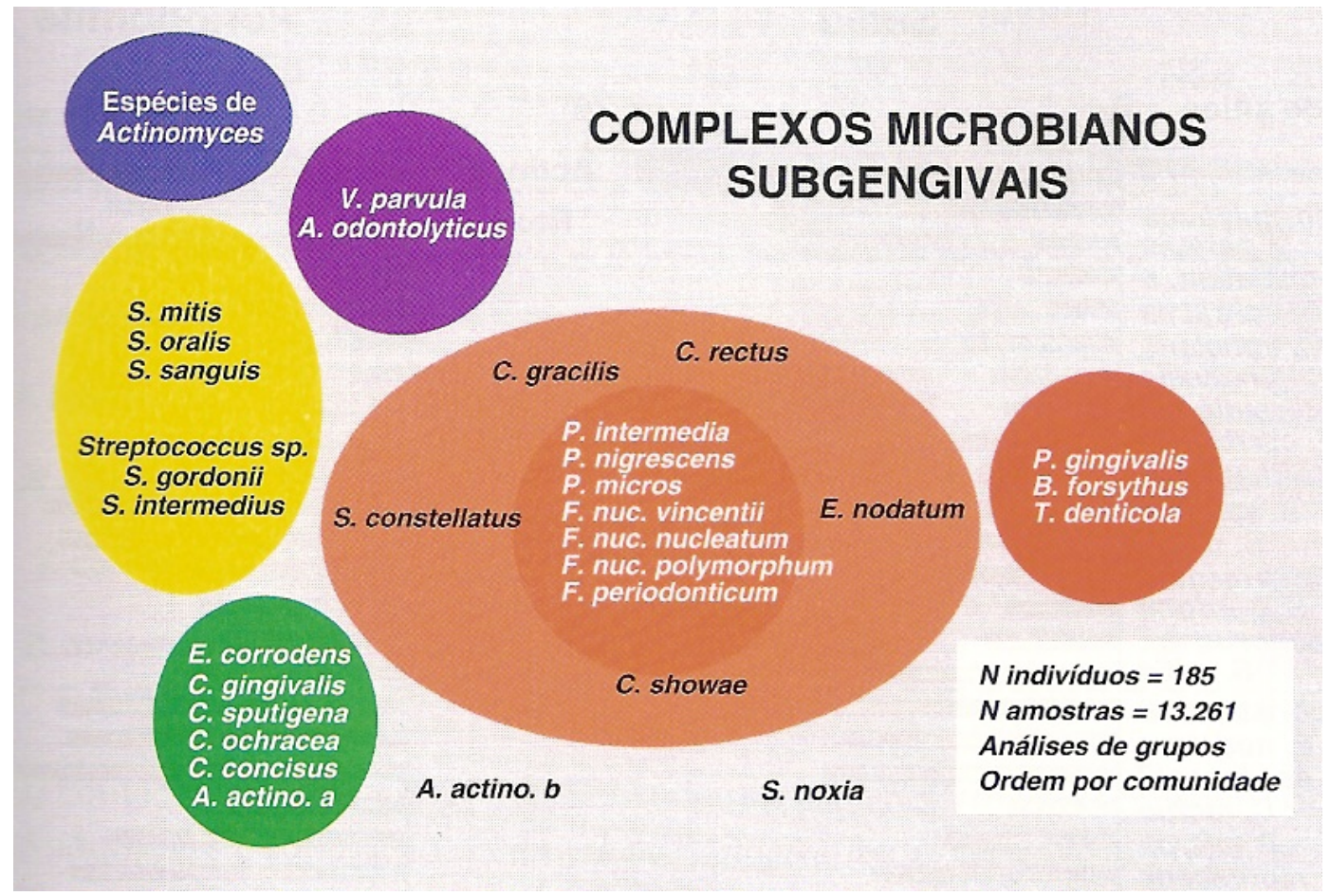

Figura 4- Diagrama da asociação entre espécies bacterianas subgengivais (Adaptado de SOCRANSKY et al. 1998). Os complexos à esquerda são compostos de espécies que parecem colonizar a superfície dentária e proliferar em estágios iniciais do desenvolvimento da placa dental. $\mathrm{O}$ complexo laranja torna-se posteriormente mais dominante em número; presume-se que espécies desse complexo atuam agregando os colonizadores iniciais. O complexo vermelho torna-se mais dominante em número e estágios tardios no desenvolvimento da PB (LINDHE et al., 2005). 


\subsubsection{Patogênese da DP e a presença de vírus no periodonto}

Alguns estudos descrevem a presença de vírus na etiologia e patogênese da DP e mostram que são vírus do tipo DNA, contraídos na infância ou no início da idade adulta através do contato com sangue, saliva ou secreções genitais (CONE, R. W. et al., 1993; CONTRERAS A. et al., 2000; CASSAI E. et al., 2003; CAPPUYNS P, 2005). Os herpesvírus parecem ser os mais importantes vírus de genoma do tipo DNA associados às patologias bucais. $\mathrm{O}$ início das infecções por herpesvírus está associado à imunidade debilitada (CONTRERAS e SLOTS, 2000).

Lesões de periodontites associadas a herpesvírus abrigam níveis elevados de bactérias periodontopatogênicas, incluindo Actinobacillus actinomycetemcomitans, Porphyromonas gingivalis, Tanerella forsythia, Prevotella intermedia, Prevotella nigrescens e Treponema denticola (LINDHE et al., 2005). Pode ser que a infecção por herpesvírus no periodonto prejudique a defesa local, permitindo por meio disso a proliferação exacerbada das bactérias periodontopatogênicas (SLOTS e CONTRERAS, 2000).

A alternância entre fase de latência e ativação da infecção por herpesvírus no periodonto, pode levar a imunossupressão local transitória e dessa forma explicar em parte a "natureza progressiva episódica" da periodontite humana, com períodos de agudização e períodos de remissão dos sinais e sintomas (SLOTS e CONTRERAS, 2000).

O tropismo tecidual das infecções por herpesvírus pode auxiliar na localização da destruição dos tecidos periodontais, e a reativação viral pode explicar porque alguns indivíduos carregam bactérias periodontopatogênicas, porém apresentam os tecidos periodontais saudáveis (SLOTS e CONTRERAS, 2000).

As doenças bucais têm sido associadas aos Vírus do Herpes Simples tipo 1 (HSV-1), Vírus do Herpes Simples tipo 2 (HSV-2), Vírus da Varicela Zoster (VZV), Vírus Epstein-Barr (EBV), Citomegalovírus Humano (HCMV), Herpesvírus Humano tipo 6 (HHV-6), Herpesvírus Humano tipo 7 (HHV-7) e Herpesvírus Humano do Sarcoma de Kaposi (KSHV) ou Herpesvírus Humano tipo 8 (HHV-8) (CONTRERAS e SLOTS, 2000). 


\subsubsection{Características do tecido periodontal doente}

O tecido periodontal acometido pela DP apresenta alteração da cor da gengiva, sangramento gengival espontâneo ou provocado, redução na resistência ao exame com sonda periodontal acompanhada ou não de retração tecidual; ao exame radiográfico, pacientes com periodontite crônica apresentam perda do osso alveolar. As sintomatologias mais relatadas são: mobilidade dental, sensação de dente crescido, halitose e dor (LINDHE, 2005).

\subsection{Herpesvírus Humano Tipo 6}

\subsubsection{Histórico}

O herpesvírus humano tipo 6 (HHV-6) foi descoberto em 1986, por Salahuddin e colaboradores, analisando cultura de linfócitos derivados do sangue periférico de indivíduos com desordens linfoproliferativas ou com Síndrome da Imunodeficiência Adquirida (AIDS). Esses pesquisadores observaram que os linfócitos apresentavam sincícios dentro de dois a quatro dias e morriam em seguida. Quando as células foram observadas ao microscópio eletrônico, foram visualizadas partículas semelhantes a um vírus da família Herpesviridae (SALAHUDDIN et al., 1986).

$\mathrm{O}$ vírus foi inicialmente denominado vírus linfotrópico para células $\mathrm{B}$ humanas (HBLV), pelo fato de estudos iniciais terem sido realizados em linfócitos B (SALAHUDDIN et al., 1986). Através de estudos realizados por Iyengar e colaboradores (1991), ficou estabelecido que este vírus possui um tropismo para linfócitos T.

\subsubsection{Classificação}

O Comitê Internacional de Taxonomia de Vírus (ICTV), classificou esse vírus na família Herpesviridae, sub-família Betaherpesviridae, gênero Roseolovírus, herpesvírus humano 6 (HHV-6).

Estudos baseados em características biológicas, imunológicas e moleculares do HHV-6, sugeriram a existência de dois grupos distintos do HHV-6 (AUBIN et al., 1991; SCHIRMER et al., 1991), os subgrupos HHV-6 A e HHV-6B. Todos os membros dessa 
subfamília possuem os mesmos padrões de ciclo replicativo e características morfológicas da família Herpesviridae, fazendo infecção persistente nas células do hospedeiro. O virion possui de 160 a $200 \mathrm{~nm}$ de diâmetro (YOSHIDA et al., 1989), com capsídeo icosaédrico apresentando 90 a $100 \mathrm{~nm}$ de diâmetro, composto de 162 capsômeros, sendo que 150 hexaméricos e 12 pentâmeros. Apresenta uma camada amorfa de proteínas, denominada tegumento, entre o capsídeo e o envelope, importante para a regulação do ciclo replicativo viral. O envelope é trilaminar, composto de glicoproteínas e poliaminas inseridas em sua superfície (PELLETT e BLACK, 1996).

\subsubsection{Morfologia Viral do HHV-6}

A morfologia da partícula viral do HHV-6 está apresentada na figura 5.

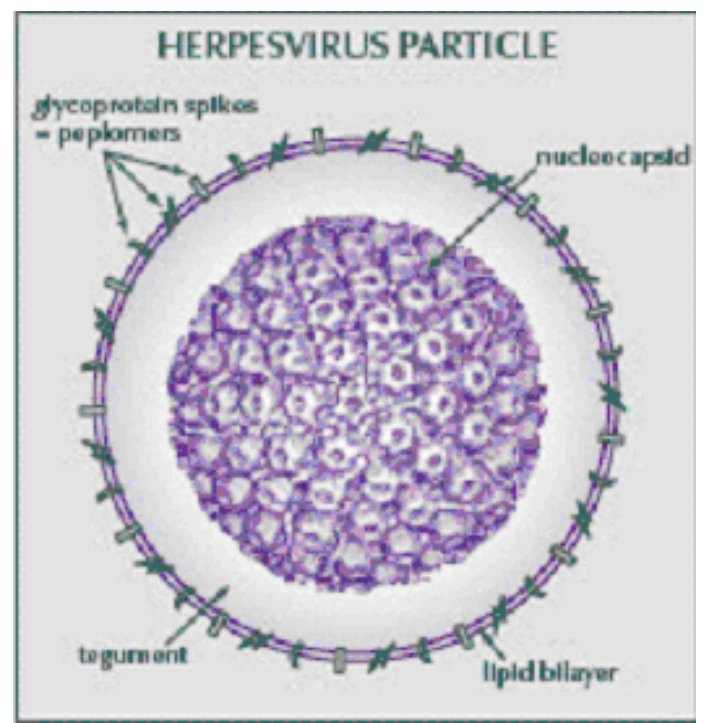

Figura 5- Vírus HHV-6 (www.drpodell.org/images/herpesvirusparticle.PNG). 


\subsubsection{HHV-6: Variantes A e B}

Cepas pertencentes a um grupo, que inclui o isolado original (estirpe GS), são principalmente isoladas de pacientes com doenças linfoproliferativas e são chamadas de variante A ou HHV-6 A e a outra, que inclui a estirpe Z-29, isolada principalmente, em material proveniente de pacientes com Exantema Súbito (ES), variante B ou HHV-6 B. A homologia na seqüência de nucleotídeos, entre as duas variantes é de $96-97 \%$ (AUBIN et al., 1993).

Estudos compararam as propriedades de variação padrão de hibridização de um HHV-6 isolado com um outro contendo um único fragmento de DNA clonado dentro de um grupo de isolados (DUNNE et. al., 1992; EFSTATIOU et al.; LINDQUESTER et al., 1997). Chegaram a conclusão que o isolado individual diferenciava-se em alguma propriedades, com já era esperado para os herpesvírus. Porém, quando os mesmos estudos foram expandidos incluindo marcadores e isolados, os isolados individuais consistentemente segregaram entre um dos dois grupos que diferiam no tropismo celular in vitro (CHANDRAN et al., 1992), efeitos na expressão das células T marcadas, reativação com painéis de anticorpos de monoclonais e clones de células T (DUNNE et al., 1992; BLACK et al., 1989; BRIGGS et al., 1988; CHANDRAN et al., 1992; IYENGAR et al., 1991), perfil de restrição de endonuclease, seqüências de nucleotídeos (BURD et al., 1993; IYENGAR et al., 1991), soroepidemiologia, e associação de doenças (CHANDRAN et al., 1992).

\subsubsection{Epidemiologia}

Estudos soroepidemiológicos mostraram que o vírus está amplamente disseminado na população mundial, podendo atingir 90\% de positividade (OKUNO et al., 1989; PARKER et al., 1993; WILBORN et al., 1994; CHALLONER et al., 1995), variando entre grupos étnicos e conforme as localizações geográficas (LEVINE et al., 1992). A atividade do HHV-6 pode estar relacionada às alterações do sistema nervoso central em pacientes com esclerose múltipla (CHALLONER et al., 1995; WILBORN et al., 1994; LUPPI et al., 1994). É citado como possível co-fator em algumas situações clínicas, como sendo um vírus oportunista em patogenias de pacientes imunocomprometidos, transplantados renais, de fígado e de medula óssea (KNOX et al., 1992; CARRIGAN et al., 1994; PILLAY et al., 1992; RUBIN et al., 1993). 


\subsubsection{Patogenicidade do HHV-6}

Os HHV-6 A e B infectam preferencialmente linfócitos CD4+ cultivados in vitro, gerando infecção produtiva, embora também possam infectar outros tipos de células de maneira produtiva ou não. A replicação viral nas glândulas salivares é observada, na infecção por HHV-6B, contribuindo para a disseminação e o isolamento do vírus na boca e na saliva. Esse vírus pode se replicar nas glândulas salivares e ser excretado na saliva, a recuperação ocorre nas glândulas genitais e no tecido cervical, sugerindo que a infecção do bebê durante o nascimento, possa ocorrer. A transmissão intra-uterina é sugerida, mas não comprovada. (EFSTATIOU et al., 1988; LAWRENCE et al., 1990; PELLET e BLACK, 1996).

\subsubsection{Exantema Súbito (ES)}

A etiologia infecciosa do Exantema Súbito (ES) foi descrita na década de 1950 através de inoculações experimentais em voluntários e em macacos Rhesus (KEMPE et al., 1950). Em 1988, o HHV-6 foi identificado como agente etiológico do ES (YOSHIDA et al., 1989).

\subsubsection{HHV-6 nos tecidos periodontais}

Nos tecidos periodontais, o HHV-6 infecta principalmente linfócitos $\mathrm{T}$ e ocasionalmente linfócitos B (FLAMAND et al., 1993; LUSSO et al., 1988). Sendo que o padrão infeccioso pode ser agravado com sinergismo entre HHV-6 e EBV, dessa maneira a interação molecular entre os dois vírus pode ser importante na patogênese da doença periodontal (FLAMAND et al., 1993).

Poucos estudos estão disponíveis sobre a ocorrência de HHV-6 nos tecidos periodontais, alguns deles sugerem que o HHV-6 apresenta pouca ou nenhuma associação com a maioria dos tipos de doença periodontal destrutiva (CONTRERAS et al., 1996; CONTRERAS et al., 1997; CONTRERAS et al., 1999). Dessa maneira se fazem necessários estudos adicionais sobre a ocorrência de HHV-6 em DP. 


\section{Conclusões}

Os resultados encontrados no presente trabalho permitem chegar as seguintes conclusões:

1) O HHV-6 foi detectado tanto no tecido periodontal acometido por periodontite crônica como no tecido periodontal saudável, atingindo uma freqüência de 2(30) 6,7\% de pacientes portadores de doença periodontal e 4(30) 13,3\% de pacientes periodontalmente saudáveis.

2) Após a caracterização molecular todas as amostras positivas para PCR e nested-PCR apresentaram homologia para variante tipo B.

3) A PCR, nested-PCR seguida de sequenciamento de nucleotídeos, mostraram ser técnicas de grande utilidade para a detecção e caracterização molecular de HHV-6 no tecido periodontal, detectando o DNA viral em $06(10 \%)$ dos 60 casos analisados neste estudo.

4) Os resultados mostram que o tecido gengival pode agir como reservatório para HHV-6. 


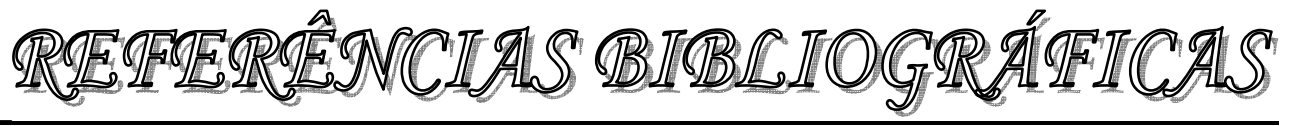




\section{Referências Bibliográficas}

ACHOUR, A.; BOUTOLLEAU, D.; SLIM, A.; AGUT, H.; GAUTHERET-DEJEAN, A. Human herpesvirus-6 (HHV-6) DNA in plasma reflects the presence of infected blood cells rather than circulating viral particles. J. Clin. Virol., v. 38, p. 280-285, 2007.

ALBANDAR, J.M.; RAMS, T.E. Global epidemiology of periodontal diseases: na onverview. Periodontology 2000, v. 29, p. 7-10, 2002.

ARAÚJO, A.C.S.; GUSMÃO, E.S.; SILVEIRA, R.C.T. Impacto das Periodontites na qualidade de vida. Rev. Periodontia, v.16, p. 83-87, 2006.

ARMITAGE, G.C. Development of a classification system for periodontal diseases and conditions. Ann. Periodontol., n.1, v.4, p. 1-6, 1999.

AUBIN, J.T.; AGUT, H.; COLLANDRE, H.; YAMANISHI, J.; CHANDRAN, B.; MONTAGNIER, L.; HURAUX, J.M. Antigenic and genetic differentiation of the two putative types of human herpesvirus 6. J. Virol. Methods, v. 41, p. 223-34, 1993.

AUBIN, J.; COLLANDRE, H.; CANDOTTI, D.; INGRAND, D.; ROUSIOUX, C.; BURGARD, M.; RICHARD, S.; HURAUX, J.M.; AGUT, H. Several groups among herpesvirus 6 atrains can be distinguished by Southern blotting and polymerase chain reaction. J. Clin. Microbiol., v. 29, p. 367-72, 1991.

BLACK, J.B.; SANDERLIN, K.C.; GOLDSMITH, C.S.; GARY, H.E.; LOPEZ, C.; PELLETT, P.E.Growth properties of human herpesvirus-6 strain Z29. J. Virol. Methods, v. 26, p. 133-145, 1989.

BRIGGS, M.; FOX, J.; TEDDER, R. S.; Age prevalence of antibody to human herpesvirus 6. Lancet, v.1, p. 1058-1059, 1988.

BURD, E. M.; CARRIGAN, D. R. Human Herpesvirus 6 (HHV-6) associated dysfunction of blood monocytes. Virus Res., v. 29, p. 79-90, 1993.

CAPPUYNS, I.; GURGERLI, P.; MOMBELLI, A. Viruses in periodontal disease: a review. Oral Dis., v. 11, p. 219-229, 2005.

CARRIGAN, D. R.; KNOX, K. K. Human herpesvirus 6 (HHV-6) isolation from bone marrow; HHV-6 associated bone marrow supression in bone marrow transplanted patients. Blood, v. 84, 10:3307-10, 1994.

\footnotetext{
* De acordo com:

ASSOCIAÇÃO BRASILEIRA DE NORMAS TÉCNICAS. NBR 6023: informação e documentação: referências: elaboração. Rio de Janeiro, 2002.
} 
CASSAI, E.; GALVAN, M.; TROMBELLI, L.; ROTOLA, A. HHV-6, HHV-7, HHV-8 in gingival biopsies from chronic adult periodontitis patients: a case-control study. $\boldsymbol{J}$. Clin. Periodontol., v.23, p.184-191, 2003.

CHALLONER, P. B.; SMITH, K. T.; PARKER, J. D.; MACLEOD, D. L.; COULTER, S. N.; ROSE, T. M.; SCHULTZ, E. R.; BENNET, J. L.; GARBER, R. L.; CHANG, M.; SCHAD, P. A.; STEWART, P. M.; NOWINSKI, R. C.; BROWN, J. P.; BURMER, G. C. Plaque- associeted expression of human herpesvirus 6 in multiple sclerosis. Proc. Natl. Acad. Sci. USA, v.92, p.7740-4, 1994.

CHANDRAN, B.; TIRAWATNAPONG, S.; PFEIFFER, B.; ABLASHI, D. V. Antigenic relationships among human herpesvirus 6 isolates. J. Med. Virol., v. 37, p. 247-254, 1992.

CONE, R. W.; HUANG, M. L. W.; ASHLEY, R.; COREY, L. Human herpesvirus 6 DNA in peripheral blood cells and saliva from immunocompetent individuals. . J. Clin. Microbiol, v. 31, p. 1262-7, 1993.

CONTRERAS, A.; FALKERLER, Jr. W. A.; ENWONWU, C. O. Human Herpesvidae in acute necrotizing ulcerative gingivitis in children in Nigeria. Oral Microbiol. Immunol., v. 12, p. 259-265, 1997.

CONTRERAS, A.; MARDIROSSIAN, A.; SLOTS, J. Herpesvirus in HIVperiodontitis. J. Clin. Peridontol., v. 28, p. 96-102, 2001.

CONTRERAS, A.; NOWZARI, H.; SLOTS, J. Herpesviruses in periodontal pocket and gingival tissue specimens. Oral Microbiol. Immunol., v.15, p. 15-18, 2000.

CONTRERAS, A.; SLOTS, J. Herpesviruses in human periodontal disease. $J$. Periodontal. Res., v.35, p. 3-16, 2000.

CONTRERAS, A.; SLOTS, J. Mammalian viruses in human periodontitis. Oral Microbiol. Immunol . v.11, p. 381-386, 1996.

CONTRERAS, A.; UMEDA, M.; CHEN, C.; BAKKER, I.; MORRISON, J. L.; SLOTS, J. Relationship between herpesviruses and adult periodontitis bacteria. $J$. Periodontol., v.70, p. 478-484, 1999.

CONTRERAS, A.; ZADEH, H. H.; NOWZARI, H.; SLOTS, J. Herpesvirus infection of inflamatory cells in human periodontitis. Oral Microbiol. Immunol., v. 14, p. 206$212,1999$.

DARVEU, R. P.; TANNER, A.; PAGE, R. C. The microbial challenge in periodontitis. Periodontol. 2000, v. 14, p. 12-32, 1997.

DI LUCA, D.; MIRANDOLA, P.; RAVAIOLI, T.; BIGONI, B.; CASSAI, E. Distribution of HHV-6 variants in human tissues, Infect. Agents Dis., v. 5, p. 203-214, 1996. 
DONLAN, R. M.; COSTERTON, J. W..Biofilms: survival mechanisms of clinically relevant microorganisms. Clin. Microbiol. Rev., v. 15, p. 167-193, 2002.

DUNNE, W. M. Jr.; DEMMIER, G. J. Serological evidence for congenital transmission of human herpesvirus 6. Lancet, v.340, p. 121-122, 1992

EFSTATIOU, S.; GOMPELS, U. A.; GRAXTON, M. A.; HONESS, R. W.; WARD, K. DNA homology between a novel human herpesvirus (HHV-6) and human cytomegalovirus. Lancet, v. 1; p. 63-4, 1988.

FABRI, G. M. C. Doença periodontal grave em pacientes com ou sem queixa de dor crônica crânio-facial: correlação dos aspectos clínicos com a análise quantitativa da substância P e do óxido nítrico do tecido gengival inflamado - Faculdade de Medicina da Universidade de São Paulo, São Paulo, 2007.

FIEZTE, E.; PROSCH, S.; REINKE, P. Cytomegalovirus infection in transplant recipients. Transplantation, v. 58, p. 675-680, 1994.

FLAMAND, L.; STEFANESCU, I.; ABLASHI, D. V.; MENEZES, J. Activation of the Epstein-Barr virus replicate cycle by human herpes virus 6. J. Virol., 1993: 67: 67686777.

GREENBERG, M.; DUBIN, G.; STEWART, J. Relationship of oral disease to the presence of cytomegalovirus DNA in saliva of AIDS patients. Oral Surg. Oral Med. Oral Pathol. Oral Radiol. Endod. 1995; 79: 175-179.

HUANG, L. M.; KUO, P. F.; LEE, C. Y.; LIU, M. Y.; YANG, C. S. Detection of human herpesvirus-6 DNA by polymerase chain reaction in serum or plasma. $\mathbf{J}$. Med. Virol., v. 165, p. 7-10, 1992.

IVENGAR, S.; LEVINE, P. H.; ABLASHI, D.; NEEQUAYE, J.; PEARSON, G. R. Soroepidemiological investigations on human herpesvirus 6 (HHV-6) infections using a newly developed early antigen assay. Inst. J. Cancer, v.49, p. 551-557, 1991.

KAMMA, J. J.; CONTRERAS, A.; SLOTS, J. Herpes viruses and periodontopathic bactéria in early-onset periodontitis. J. Clin. Periodontol., v. 28, p. 879-885, 2001.

KEMPE, C. H.; SHAW, E.B.; JACKSON, J. R.; SILVER, H. K. Studies on the etiology of exanthema subitum (roseola infantum). J. Pediatr., v. 37, p. 561-568, 1950.

KINANE, D. F.; PETERSON, M.; SATHOPOUlOU, P. G. Environmental and other modifying factors of the periodontal diseases. Periodontology, v. 40, p. 107-119, 2006.

KNOX, K. K.; CARRIGAN, D. R. In vitro supression of bone marrow progenitor cell differentiation by human herpesvirus 6 infection. J. Infect. Dis., v. 78, p. 1381-84, 1992.

KUBAR, A.; SAYGUN, I.; ÖZDEMIR, A.; YAPAR, M.; SLOTS. Real-time polymerase chain reaction quantification of human cytomegalovirus and Epstein-Barr 
virus in periodontal pockets and the adjacent gengiva of periodontitis lesions. $\boldsymbol{J}$. Periodontol. Res., v. 40, p. 97-104, 2005.

LAWRENCE, G. L.; CHEE, M.; CRAXTON, M. A.; GOMPELS, U.A.; HONESS, R. W.; BARRELL, B. G. Human herpesvirus 6 is closely related to human cytomegalovirus. J. Virol., v. 64, p. 287-99, 1990.

LEVINE, P. H.; JAHAN, N.; MURARI, P.; MANAK, M.; JAFFE, E. S. Detection of human herpesvirus 6 in tissues involved by sinus histicytosis with massive Iymphadenophaty (Rosai-Dorfman disease). J. Infect. Dis., v. 166, p. 291-5, 1992.

LINDHE, J.; KARRING, T.; LANG, N. P. Tratado de periodontia clínica e implantologia oral. São Paulo: Guanabara Koogan, 2005.

LINDQUESTER, G. J.; O’BRIAN, J. J.; ANTON, E .D.; GREENAMEYER, C. A.; PELLETT, P. E.; DAMBAUGH, T. R. Genetic content of a 20,9 kb segment of human herpesvirus 6B strain Z29 spanning the homologs of human herpesvirus 6A genes U4057 and containing the origin of replications. Arch. Virol., v. 142, p. 1023-7, 1991.

LÖE, H.; ANERUD, A.; BOYSEN, H. The natural history of periodontal disease in man: prevalence, severity and extent of gingival recession. J. Periodontol., v. 63, p. 489-495, 1992.

LÖE, H.; THEILADE, E.; JENSEN, S. B. Experimental gingivitis in man. $\boldsymbol{J}$. Periodontol., v. 36, p. 177-187, 1965

LUPPI, M.; BAROZZI, P.; MARASCA, R.; TPRELLI, G. Human herpesvirus 6 infection in normal brain tissue. J. Infect. Dis., v. 169, p. 943-44, 1994.

LUSSO, P.; GALlO, R. C.; DEROCCO, S. E.; MARKHAN, P. D. CD4 is not the membrane receptor for HHV-6. Lancet, v. 1, p. 730, 1989.

MARDIROSSIAN, A.; CONTRERAS, A.; NAVAZESH, M.; NOWZARI, H.; SLOTS, J. Herpesviruses 6,7 and 8 in HIV - and non -HIV-associated periodontitis. $J$. Periodontal Res., v.35, p. 278-284, 2000.

MARSH, P. D. Dental plaque as a microbial biofilm. Caries Res., v. 38, p. 204-211, 2004.

MICHALOWICZ, B. S.; RONDEROS, M.; CAMARA-SILVA, CONTRERAS, A.; SLOTS, J. Human herpesviruses and Porphyromonas gingivalis are associated with juvenile periodontitis. J. Periodontol., v. 71, p. 981-988, 2000.

MINISTÉRIO DA SAÚDE. Secretaria de Atenção à Saúde. Departamento de Atenção à Básica. PROJETO SB BRASIL 2003. Condições de saúde bucal da população brasileira 2002-2003: resultados principais. Brasília: Ministério da Saúde, 2005.

NANCI, A.; BOSSHARDT, D. D. Structure of periodontal tissues in health and disease. Periodontology, v. 40, p. 11-28, 2006. 
OKUNO, T.; TAKAHASHI, K.; BALACHANDRA, N.; SHIRAKI, K.; YAMANISHI, K.; TAKAHASHI, M.; BABA, K. Seroepidemiology of human herpesvirus 6 (HHV-6) infection in normal children and adults. J. Clin. Microbiol., v. 27, p. 651-3, 1989.

OSTWALD, C.; MULLER, P.; BARTEN, M. ET AL. Human papillomavirus DNA in oral squamous cell carcinomas and normal mucosa. J. Oral Pathol. Med. v. 23, p. 220225, 1994.

PARKER, C. A.; WEBER, J. M. An enzyme-linked immunosorbent assay for the detectin of IgG and IgM antibodies to human herpesvirus type 6. J. Virol. Methods, v. 41, p. 256-276, 1993.

PARRA, B.; SLOTS, J. Detection of human viruses in periodontal pockets using polymerase chain reaction. Oral Microbiol. Immunol. v. 5, p. 289-293, 1996.

PELLETT, P.E.; BLACK, J. B. Human herpesvirus 6. In: Fields, B. N.; Knipe, D. M.; Howley, P. M., Virology. 3 ed. New York: Raven Press, 1996. p. 2587-2608.

PILLAY, D.; WEBSTER, A.; PRENTICE, H.; GRIFFITHS, P. D. Risk factors for viral reactivation following bone marrow transplantation. Ann. Hematol., v. 64, p. 148-151, 1992.

RHOADS, M. P.; MARGARET, A. S.; ZERR, D. M. Family saliva sharing behaviors and age of human herpesvirus-6B infection. J. infect., p. 623-626, 2007.

RIVERA-HIDAlgO, F. Smoking and periodontal disease. J. Periodontol., v. 57, p. 617-624, 1986.

RUBIN, R. H. Infectious disease complications of renal transplantation. Kidney Inst., v. 44, p.221-36, 1993.

SALAHUDDIN, S. Z.; ABLASHI, D. V.; MARKHAM, P. D.; JOSEPHS, S. F.; STUZENEGGER, S.; KAPLAN, M.; HALLIGAN, G.; BIBERFELD, P.; WONGSTALL, F.; KRAMARSKI, B.; GALLO, R. C. Isolation of a new virus, HBLV, in patients with lymphoproliferative disorders. Science, v.234, p. 596-601, 1986.

SANTOS, N. S. O.; ROMANOS, M. T. V.; WIGG, M. D. Introdução à Virologia Humana. Rio de Janeiro: Guanabara Koogan, 2002.

SAYGUN, I.; KUBAR, A.; ÄZDEMIR, A.; YAPAR, M.; SLOTS, J. Herpesviralbacterial interrelations in aggressive periodontitis. J. Periodontol. Res., v. 39, p. 207$212,2004$.

SCHIMER, E. C.; WYATT, L. S.; YAMANISHI, K.; RODRIGUEZ, W. J.; FRENKEL, N. Diferentiation between two distinct classes of viruses now classified as human herpesvirus 6. Proc. Natl. Acad. Sci., v. 88, p. 5922-5926, 1991.

SHIRAKI, K.; MURAY, T.; OKUNO, T.; YAMANISHI, K.; TAKAHASHI, M. Physicochemical characterization of human herpesvirus-6 infectivity. J. Gen. Virol., v. 72, p. 167-72, 1991. 
SIQUEIRA, J. T. T. Dor em odontologia: breve histórico e perspectivas. In: SIQUEIRA, J. T. T.; TEIXEIRA, M. J. (Ed.). Dor orofacial: diagnóstico, terapêutica e qualidade de vida. Curitiba: Editora Maio, 2001. p. 3-14.

SLOTS, J.; CONTRERAS, A. Herpesviruse: a unifying causative factor in periodontitis? Oral Micróbiol. Immunol., v. 15, p. 277-280, 2000.

SOCRANSKY, S. S.; HAFFAJEE, A. D. The bacterial etiology of destructive periodontal disease: current concepts. J. Periodontol., v. 63, p.322-331, 1992.

SOCRANSKY, S. S.; HAFFAJEE, A. D.; CUGINI, M. A.; SMITH, C.; KENT, R. L. Jr. Microbial complexes in subgingival plaque. J. Clin. Periodontol., v. 25, p.134-144, 1999.

SOUTHERLAND, J. H.; TAYLOR, G. W.; MOSS, K.; BECK, J. D.; OFFENBACHER, S. Commonality in chronic inflammatory diseases: periodontitis, diabetes, and coronary artery disease. Periodontology, v. 40, p. 130-143, 2006.

SUSIN, C.; ALBANDAR, J. M. Aggressive periodontitis in an urban population in southern Brasil. J. Periodontol., v. 76, p. 468-475, 2005.

SUSIN, C.; DALLA VECCHIA, C. F.; OPPERMANN, R. V.; HAUGEJORDEN, O.; ALBANDAR, J. M. Periodontal attachment loss in an urban population of Brazilian adults: effect of demographic, behavioral, and environmental risk indicatiors. $\boldsymbol{J}$. Periodontol., v. 75, p. 1033-1041, 2004.

TAKASHIBA, S.; NARUISHI, K. Gene polymorphisms in periodontal health and disease. Periodontology, v. 40, p. 94-106, 2006.

TANTIVANICH, S.; LAOHAPAND, P.; THAWEEBONN, S.; DESAKORN, V.; WUTHINUNTIWONG， P.; CHATERMTARANUKUL， S.; PANSR,I P.; AMARAPAL, P.; BALACHANDRA, K.; CHATRATITA, W.; DHEPAKSON. Prevalence of Cytomegalovirus, Human Herpesvirus-6 and Epstein-Barr virus in periodontitis patients and healthy subjects in the Thai population. Southeast Asian $J$. Trop. Med. Public. Health, v. 35, p. 635-640, 2004.

TAVAKOLI, N. P.; NATTANMAI, S.; HULL, R.; FUSCO, H.; DZIGUA, L.; WANG, H.; DUPUIS, M. Detection and Typing of human Herpesvirus 6 by Molecular Methods in Specimens from Patients Diagnosed with Encephalitis or Meningitis. J. Clin. Microbiol., v. 45, p. 3972-3978, 2007.

VAN DEVANTER, D.; WARRENER; BENNET, L.; SCHULTZ, E. R.; COULTER SILVIJA.; GARBER, L. R.; ROSE, M. T. Detection and Analysis of Diverse Herpesviral Species by Consensus Primer PCR. J. Clin. Microbiol., v. 34, p.1666-1671, 1996.

VIRUS HHV-6. Disponível em: <www.drpodell.org/images/herpesvirusparticle>. Acesso em: 20 maio 2008. 
WATANABE, S. A.; CORREIA-SILVA, J. F.; HORTA, M. C. R.; COSTA, J. E.; GOMEZ, R. S. EBV-1 and HCMV in agrgesive periodontitis in Brazilian patients. Braz. Oral Res., v. 21, p. 336-341, 2007.

WILLBORN, F.; BRIMANN, V.; SCHIMDT, C. A.; NEIPEL, F.; GELDERBLOM, H.; SIEGERT, W. Herpesvirus type 6 in patients undergoing bone marrow transplantation: serologic features and detection by polimerase chain reaction. Blood, v. 83, p. 3052-8, 1994.

YALCIN, S.; YAMANISHI, K.; LENNETTE, D. A.; LENNETTE, E. T. Diagnostic procedures for viral, rickettsial and chamydial. Washington, D.C.: American Public health association, 1995. p. 397-405.

YAMAZAKI, Y.; NAKAJIMA, T. Antigen specificity and $\mathrm{T}$ cell clonality in periodontal disease. Periodontology, v. 35, p. 75-100, 2004.

YAN-MIN- WU; JIE, Y.; LI-LI, C.; WEI-LIAN, S.; ZHI-YUAN, G. Infeccion frequency of Epstein-Barr virus in subgingival samples from patients with different periodontal status and its correlation with clinical parameters. J. Zhejiang Univ. Sci. B., v. 7 , p. $876-883$.

YEUNG, S. C.; STEWART, G. J.; COOPER, D. A.; SINDHUSAKE, D. Progression of periodontal disease in HIV seropositive patients. J. Periodontol. v. 64, p. 651-657, 1993.

YOSHIDA, M.; UNO, F.; BA,I Z. L.; YAMADA, M.; NII, S.; SATA, T.; KURATA, T.; YAMANISHI, K.; TAKAHASHI, M. Electron. Microscopic study of a herpesvirustype isolated from na infant with exanthem subitum. Microbiol. Imunol., v. 33, p. 14754, 1989.

YOSHIE, H.; KOBAYASHI, T.; TAI, H.; GALICIA, J. C. The role of genetic polymorphisms in periodontitis. Periodontology, v. 43, p. 102-132, 2007. 